\title{
A Critical Discourse Analysis of the Link between Professional Culture and Organisational Culture
}

\begin{abstract}
Purpose - Despite the fundamental role of culture in an organisational setting, little is known of how organisational culture can be sometime determined/influenced by professional culture, particularly in the global south. Using Nigeria as a research focus, this article uses critical discuss analysis to examine the link between professional and organisational culture.
\end{abstract}

Design/Methodology/Approach - This study uses qualitative research approach to establish the significance of professional culture as a determinant of organisational culture among healthcare organisations.

Findings - We found that the medical profession, in Nigeria, is replete with professional duties and responsibilities, such as professional values and beliefs, professional rules and regulations, professional ethics, eagerness to fulfil the Hippocratic Oath, professional language, professional symbols, medicine codes of practice, and societal expectations, all of which conflate to form medical professionals' values, beliefs, assumptions, and the shared perceptions and practices upon which the medical professional culture is strongly built. Thus, making the medical professional culture stronger and more dominant over the healthcare organisational culture.

Research Limitations/Implications - The extent to which the findings of this research can be generalised is constrained by the limited and selected sample of the research.

Practical Implications - The primacy of professional culture over organisational culture may have dysfunctional consequences for HRM, as medical practitioners are obliged to stick to medical professional culture over human resources practices. Hence, human resources departments may struggle to cope with the behavioural issues that arise due to the dominant position taken by the medical practitioners. This is because the cultural system (professional culture), which is the configuration of beliefs, perceived values, code of ethics, practices, etc. shared by medical doctors, subverts the operating system. Therefore, in the case of healthcare organisations, HRM should support and enhance the cultural system (the medical professional culture) by offering compatible operating strategies and practices.

Originality/Value - This article provides valuable insights into the link between professional culture and organisational culture. It also enriches debates on organisational culture and professional culture. We therefore contend that a strong professional culture can overwhelm and eventually become an organisational culture.

Keywords: Organisational culture, professional culture, healthcare practitioners, medical doctors, cultural interplay, critical discourse analysis, CDA

\section{Authors}

Adisa, Toyin. University of East London, UK: t.adisa@uel.ac.uk 
Oruh, Emeka. University of Portsmouth, UK: emeka.oruh@port.ac.uk

Akanji, Babatunde: Elizade University, Ondo State Nigeria:

babatunde.akanji@elizadeuniversity.edu.ng

\section{Introduction}

The dominance of organisational culture in management and organisational research over the past three decades is a recognised fact (Ogbonna and Harris, 2014). The exponential interest in the concept is perhaps because many successful academic careers have been built on studies addressing sundry aspects of culture (Hofstede, 1980; Smircich, 1983; Schein, 1984; Schein, 1985; Torsello, 2019). Similarly, business and organisation practitioners' interest in research on organisational culture has remained strong, with many studies highlighting business executives' approval of the importance and advantages of good and proactive culture management (see Worrall, Parkes and Cooper, 2004; Pfister, 2009).

Professionals, however, occupy a vital and powerful role in the society because they have specialised knowledge that not every member of society has but which is very important to the life of the society (Bedzow, 2019; Brien, 1998). This assertion supports the study of Hughes (1958), in which he argues that one of the unique attributes of a profession is that its members have specific and distinctive expertise that a non-professional does not have.

However, empirical studies on professional culture do not match the catalogue of research that has been undertaken on organisational culture over the years, and the dearth of empirical evidence in the literature about the relationship between professional and organisational culture is evident (see Smith and Webster, 2009). Specifically, Degeling et al. (2001) note that there is a dearth of critical scholarly perspectives that corroborate the interplay between organisational culture and the professional groups working within an organisation.

We therefore employ critical discourse analysis (CDA) to analyse the data. CDA deals with how texts represent organisational and social practices (Fairclough, 1992), emphasising the understanding of power relations, cultural dynamics (Wodak and Meyer, 2009), organisational rhetoric (Koca-Helvaci, 2015), and the 'representation gap' (Acas, 2012, p. 2) among others. By using CDA, we respond to the call by Bailey, Townsend and Luck (2009, p. 285) to broaden perspectives on 'new industrial relations' and organisational behaviour discourse with the aim of allowing alternative views and voices to be heard (Legge, 1995). 
CDA can be instrumental in bringing alternative views to the fore (Fairclough, 2014), specifically concerning how professional culture can overwhelm organisational culture. This is because professionals occupy crucial and powerful roles in society by using their uncommon specialised knowledge for the overall benefit of society (Brien, 1998). Our approach is consistent with prior studies (Bailey et al., 2009; Koca-Helvaci, 2015; Ford and Gillan, 2016) that have also used CDA to explore organisational behaviours, albeit in the context of employment relations and human resource management (HRM) (Vaara and Tienari, 2008).

This article thus makes two important contributions. First, it contends that a strong professional culture can overwhelm and eventually become an organisational culture, which every member of organisation will embrace and hold in high esteem. Second, it contributes to the extant literature on organisational culture by bringing the relationship between professional culture and organisational culture to the fore. These contributions add value to and provide relevant insights on organisational culture for researchers and practitioners.

Therefore, this article provides an opportunity to enhance our understanding of professional and organisational culture and its attendant implications for employees and organisations. In pursuing these objectives, we use a qualitative research approach involving face-to-face semistructured interviews with 44 health professionals (medical doctors) in Nigerian health organisations (hospitals).

Nigeria, a country that constitutes an under-researched setting in terms of this subject and whose healthcare sector is under the shadow of underdevelopment has been chosen as the research focus of this article. Additionally, Nigeria arguably represents one of the most important players in developing countries in terms of discourse and issues on organisational culture and professionalism due to its population size, which is estimated at over 200 million people (Worldometers, 2020).

Thus, the main research question that this study aims to answer is: What is the link between professional culture and organisational culture? The sub-research questions are: (a) what is the notion of professional culture and organisational culture and what differences exist between the two types of culture? (b) What conflicts exist between professional and organisational culture and which takes priority when they conflict? (c) Which of the cultures is dominant in an organisation and why?

In answering the above questions, the study employs CDA to unpack a lexical pattern and strategies to establish the health professionals' views on the potential of professional culture 
for shaping organisational culture. This article is structured as follows. The article starts with a brief overview of organisational cultures, followed by a discussion of professional culture. The nexus between professional culture and organisational culture is then discussed, followed by a discussion of medical culture and the theoretical lens for the study. Subsequently, an explanation of the methodology employed in the study is given, along with an analysis of the findings thereof. The article concludes with a discussion of the findings and an outline of the implications.

\section{Organisational Culture in Context}

Although Smircich's (1983) description of culture as a 'root metaphor' and Schein's (1985) levels of culture (artefacts, values, and assumption) were targeted at improving clarity concerning the definition of organisational culture, yet several competing frameworks have further added to the complexity concerning the study of the concept over the years (Ogbonna and Harris, 2014). There are varying perspectives according to which culture can be explored, and choosing a specific perspective as the most apt can be misleading (Bourn and Ezzamel, 1986).

Culture is an abstraction that produces powerful forces that dominate and control people in their social and organisational lives (Mathew, 2019; Schein, 2010), and it is inseparable from an organisation (Smircich, 1983). Culture is a collective programming of minds that distinguishes members of one group from another (Hofstede, 1991). In a broad sense, it is an integrated pattern of human behaviour involving language, thoughts, communications, actions, beliefs, customs, values, and institutions of racial, ethnic, religious, or social groups (Office of Minority Health, 2002; Boutin-Foster, 2008).

Building on this definition, however, organisational culture can be defined as 'the pattern of shared values and belief that help individuals understand organisational functioning and thus provide them with norms for behaviour in the organisation' (Deshpande and Webster, 1989, p. 4). For Schein, (1985), organisational culture refers to the values, beliefs, traditions and practices shared by an organisation's members. However, despite the panoply of studies on organisational culture (more than 4,600 articles have been published on the concept since 1980 [Pinho et al., 2014]), there is no universally accepted definition of the concept (Riivari et al., 2012).

However, a critical look at all the definitions shows there is a consensus among organisational researchers that organisational culture dictates to the organisation's members what is 
acceptable within and outside the organisation and what is not (see Hofstede, 1980; Schein, 1985; Deshpande and Webster, 1989). Some organisations do not care about what their members do outside the organisations, but some strongly emphasise what they do outside the organisation. For example, army officers are expected to comport themselves in an honourable and polite manner even when they are not on duty, and violation of this code of conduct attracts a severe punishment. Each organisation has its unique culture that develops overtime to reflect the organisation's identity (Day, 2020; McDermott and O'Dell, 2001). However, many researchers have highlighted the importance of subculture in cultural research (see Van Maanen and Barley, 1985; Morgan and Ogbonna, 2008).

Parker (2000) pointed out the linguistic problems associated with the term 'subculture' and argued that these problems reduce the explanatory power of subculture in organisational study. Morgan and Ogbonna (2008) are nevertheless resolute in their argument that the term 'subculture' does not denote inferior, subordinate, or dysfunctional culture in any respect: rather, it means that organisational culture is a combination of many cultures. It should be noted that the primary objective of this study, however, is not to provide an extensive review of the definitions of organisational culture. Rather, its aim is to unpack the essence of professional culture within the ambience of organisational culture. This will enhance our understanding of professional culture within the framework of this study.

\section{Understanding Professional Culture}

Professionals are fundamentally distinct from those performing other non-professional jobs in terms of their specialised expertise (Hughes, 1958), symbols (Greenwood, 1957), esoteric knowledge, and unique languages (Helmreich and Merritt, 1998). The main elements of a profession and therefore professionalism are autonomy and protection of independence (Freidson, 1970). The culture of a profession is deeply rooted in its group members by a sheer sense of unity and bonds of collective identity (Goode, 1957). Van Maanen and Barley (1985) refer to these groups as 'occupational communities', which create and sustain unique work cultures consisting of ritual tasks and standards for proper behaviour and code of practice, many of which override any new work arrangements introduced by new managerial practices (also see Kessler and Purcell, 1996).

Professional culture develops as different professions evolve, and it is deeply attached to their history and other social factors (Hall, 2005). Typically, the values and norms of a profession are sustained and exemplified by the senior members of that profession. These values and 
norms are then passed onto the new members. Therefore, professional culture is a collective programming of the minds of occupational groups (Herkenhoff, 2010), which specifies behaviours that are proper and acceptable in each profession (Boyatzis, 1982). Professional culture is often shaped and guided by the profession's history, the attributes of the professional tasks, the associated risks and responsibilities, and the characteristics of its members (Helmreich and Merritt, 1998).

Professional culture not only dictates tasks and social norms at work, it also defines the entire work environment, including what makes sense (in terms of behaviours) and the necessary procedures among a professional group (Rapisarda et al., 2020; Janus and Browning, 2014). It has a substantive inertia, and change requires time and a sequence of interventions (Helmreich and Merritt, 1998). It should be noted that even though professional culture is often classified as a subculture of a national or organisational culture (Hofstede, 1980; Scott et al., 2003), in some cases, it is stronger, distinct, and influential (Helmreich and Merritt, 1998), and it overrides organisational culture and becomes dominant. This always happens in organisations dominated by professional employees (Bloor and Dawson, 1994). According to Ott (1989, p. 80 ), the culture of an organisation dominated by professionals will be hugely influenced by the professional culture of those professionals.

Furthermore, observations by Bloor and Dawson (1994) have suggested that professional culture is similar to organisational culture as long as it exists within an historical context and a professional environment that shapes the professionals working practices and professional codes, beliefs, values, and rites. Professional culture provides cultural values and practices that are adapted into organisational culture. Therefore, the symbiosis between professional culture and organisational culture is not conflictual; rather, it is mutually interwoven.

\section{The Nexus Between Organisational Culture and Professional Culture}

Culture is a multifaceted framework within which individuals and groups function (Helmreich and Merritt, 1998). This attribute of culture applies to both organisational culture and professional culture. It is important to understand the similarity between these two cultures. Just like an organisation, a profession is a group of people who share values, attitudes (Helmreich and Merritt, 1988), norms and assumptions (Schein, 2010), and social ideals and beliefs (Janus and Browning, 2014).

Organisations differ in their components and skills. Some organisations employ different types of professionals, while others are predominantly non-professional in their type and therefore 
employ few specialist professionals. The number and importance of professionals working within an organisation will determine how organisational culture and professionalism affect each other (Bloor and Dawson, 1994). Professional culture is a collective programming of the minds of occupational groups (Herkenhoff, 2010) and specifies the behaviour that is proper and acceptable in each profession (Boyatzis, 1982).

However, the professional culture of medicine is an essential part of the medical system (Scott et al., 2003). It is so strong that it is dominant in health organisations and is often regarded as the culture of the organisation (Montgomery et al., 2009; Scott, 2003). The medical profession involves a great deal of professional responsibilities and duties beyond the actual role of treating patients (such as professional beliefs, professional rules and regulations, professional ethics, compliance with the Hippocratic Oath, and societal expectations) that conflate and form their values, beliefs, basic assumptions, and the shared perceptions and practices upon which the profession's culture is strongly built.

Despite that, a professional culture is a subculture of organisational culture, it is strong, dominant, and often referred to by health professionals as their organisational culture. Furthermore, a study by Bloor and Dawson (1994) suggests that professional culture is similar to organisational culture if it exists within an historical context and professional environment that shape the professionals' operating practices and professional codes, beliefs, values, and rites. Professional culture provides cultural values and practices that are absorbed into organisational culture. Therefore, the relationship between professional culture and organisational culture is not conflictual; rather, it is mutually interwoven. In medicine, however, organisational culture is a good representation of professional culture. Organisational culture is treated as synonymous to professional culture in this study.

\section{Medical Culture}

It has been argued that culture is an organisational feature that cannot be easily copied (Schein, 2010; Ireland and Hitt, 1999). This is consistent with the claims that every organisation has its own unique and specific culture (Sun, 2008). In medicine, according to Bloor and Dawson (1994), both professions and organisational cultures are products of their histories, and internal and external factors similarly shape both. The culture of medicine can be described as the language, thought processes, styles of communication, customs, and beliefs that characterise the profession of medicine (Boutin-Foster, 2008). However, Bloor and Dawson (1994) argue 
that medical culture comprises a collection of interacting subcultures that allow health professionals to interact and develop new knowledge and extend their cultural boundaries.

Moreover, a hospital is an organisation or a work setting that assembles a group of professionals, each with its specialised knowledge and interests as well as its own values and norms. Nonetheless, a hospital's organisational culture is not homogeneous; in fact, it is a complex institution with multiple and conflicting goals (Karassavidou and Glaveli, 2011).

Hospitals vary in their cultures (Speroff et al., 2011). They are multicultural organisations with different subcultures within distinct professional and occupational groups, divisions, and teams working together (Karassavidou and Glaveli, 2011). Most literature on organisational culture has not been matched by a parallel assessment of organisational culture in a hospital setting. Thus, limited attention has been paid to the healthcare work environment and how it influences prominent individuals such as doctors and nurses and even the organisational outcomes (Rathert et al., 2009; Montgomery et al., 2011).

Hospital culture is part of medicine's professional culture, and this culture defines the professionals who are working in health organisations. Despite the common bonds and the spirit of unity among medical professionals, medicine does not have a monolithic culture. Rather, there are subcultures that develop around various specialties (such as anaesthesia, surgery, and pathology) and members of each group differentiate themselves from other groups (see Helmreich and Merritt, 1998).

\section{Conceptual Framework}

In the past 30 years or so, organisational culture has undoubtedly remained a dominant topic in management and organisational studies (Ogbonna and Harris, 2014). Furthermore, as the extant literature has evidenced (Hofstede, 1980; Smircich, 1983), the growing interest in the concept may not be limited to the sundry cultural ethos that has successfully shaped and influenced academic career paths in recent times. Specifically, field commentators such as Worrall et al. (2004) and Pfister (2009) observed the rise in the number of business executives acknowledging their approval of proactive management dynamics, central and advantageous to sound organisational culture.

Nonetheless, while organisational culture is continuing to gain traction, not very much has been done by contemporary field scholars and practitioners to unearth the imperatives of professional culture in the shaping of organisational culture (Degeling et al., 2001). In his 
ground-breaking study of professionalism and societal matters, Brien (1998) noted that professionals occupy a vital and powerful role in society, given their unique specialised knowledge and expertise (among other attributes) that according to Hughes (1958), nonprofessionals do not have. It is therefore important to explore this view, according to which professional culture is indeed the bedrock for building sound organisational culture. In bringing this alternative perspective to bear in the discourse on Nigeria's organisational ethos, CDA, which relies on text and context offers critical perspectives to organisational behaviours, practices, and rhetoric (Fairclough, 1992; Wodak, 2001), can be appropriated to help identify the professional/organisational cultural link.

As Wodak (2000) notes, CDA ruptures human/organisational reality in social (Fairclough and Wodak, 1997), cultural (Fairclough, 2003), political (Peled-Elhanan, 2010), economic (Graham and Luke, 2011), and ideological (Fairclough, 1992, 2014) contexts, all of which can be instrumental variables in revealing the nexus between professional ethos and organisational culture. For Van Dijk (2008a; 2008b), CDA is a problem-oriented and multi-modal meaningmaking language tool. It explores how language/discourse is used to understand organisational beliefs, values, and associated ways of doing things. In Lawton's (2013, p. 107) words, it is a process of understanding 'language in use'.

Bray et al. (2005) explained that CDA has inherent appeal for industrial relations (IR) and organisational behaviour scholars. It aims to 'uncover, demystify, or otherwise challenge dominance...CDA is thus "engaged and committed", representing "a form of intervention in social practice and social relationships" (Bray et al., 2005, p. 10). Hence, CDA is thus consistent with the approach of this current study i.e. the perspective of professionalorganisational culture. It is also committed to pursuing inter and multidisciplinary research to further understand issues surrounding work and related phenomena that are sensitive to differing ideological views (Bray et al., 2005), from, for instance, professional and organisational culture can be evaluated.

Furthermore, this article maintains that linking professional culture to organisational culture essentially begins with micro-level issues, such as language choice and use, developing to frame organisational discourse (meso-level issues), and then dealing with wider societal issues (macro-level issues) (Fairclough, 2014). We argue that exploring these types of micro-level (discursive) elements can help to understand the contradictions, complexities, and ambiguities in making this link that easily pass unnoticed in more traditional approaches to text analysis 
(Wodak and Meyer, 2009). Hence, texts and contexts constitute a sense-making arena (Wodak, 2001), which can help in understanding the professional-organisational cultural nexus. Thus, choice of words (diction) or lexis is not framed essentially by organisations; rather, it is shaped by patrimonial, institutional, and cultural paradigms that are prevalent in a social space (Fairclough, 1995). In operationalising this, lexicalisation (use of lexis or choice of words) is rooted in some definite ideologies, cultures, and social norms and values (Van Dijk, 2008a).

\section{Research Methodology}

We adopted a qualitative interpretivist method in analysing the data for this study. This means that words were used to interpret social reality. We considered reality as the result of social construction and interaction (Silverman, 2006). Furthermore, given that the research is exploratory in nature and seeks to identify a range of factors that impact organisational behaviour (culture and professionalism), the qualitative method surpasses the problems of categorical imposition that are characteristic of survey research. Therefore, our approach represents participants' opinions more accurately (Alvesson and Deetz, 2000). We consequently sought an understanding of the link between professional culture and organisational culture in Nigeria premised on the views of key stakeholders: medical practitioners (doctors) in both public and private hospitals (Saunders et al., 2012).

The disparity in individuals' views sought through interviews and focus groups (and shadow reports) thus support the multiple perceptions on reality that are consistent with the interpretivist method. Consequently, it was vital to identify a data collection tool that would be consistent with the qualitative interpretivist method. Accordingly, following Patton (2012), 'there is a very practical side to qualitative research methods that simply involves asking openended questions of people...in real-world settings in order to solve problems' (p. 89). Hence, we use interviews and a focus group. The study is inductive, meaning that the theory was not tested. However, the data gathered shapes new ideas and frames direction of research (Silverman, 2006).

Twenty-five face-to-face semi-structured interviews were conducted with medical doctors in Nigeria. The interviews lasted between 50 and 90 minutes. They were digitally recorded and transcribed verbatim. The semi-structured nature of the interviews permits flexibility and also enables the identification of the voice inflections, emotions, and body language of interviewees (Saunders et al., 2012), especially when dealing with sensitive matters/issues (Okpu, 2016). 
As noted by Bryman (2012), the use of semi-structured interviews enables us to gather specific and rich data that is vital to achieving the research's aim and objectives. As a two-way communication process, the data gleaned from this exercise gave us the platform to ask more questions stemming from the reactions of the participants concerning what can be regarded as a significant response.

A focus group session (involving seven participants in each session) was also conducted and lasted about 75 minutes. Focus groups help in gaining diverse but congruent views, which interviews might not provide (Bryman, 2012). It is an 'information rich' tool, pertinent for achieving 'data saturation' (Krueger and Casey, 2000, p. 25) when combined with the interview method. Focus groups further encourages participants to give genuine information unwittingly through its interactive mechanism, which increases validity. The focus group sessions help to identify trends in thoughts and patterns of events without persuasion from the facilitator.

In terms of the sampling method, the interviewees and discussants in both interviews and focus group sessions were medical doctors in Nigeria. Hence, they were familiar with the Nigerian healthcare sector and the cultures thereof. Importantly, the respondents all met the eligibility criteria: registration with the Medical and Dental Council of Nigeria (MDCN), an umbrella association for all doctors practising in Nigeria.

\section{Insert Table 1 about here}

Table 1 provides a detailed list of the participants in the study. The focus group involved seven medical practitioners. It is worth noting that size is not really an issue in qualitative research methods (Bryman, 2012). What matters is data saturation (Patton, 2012), which helps researchers to know if they have reached a stage at which further interviews are not uncovering new themes (Saunders et al., 2012).

\section{The Analytical Framework}

Data was transcribed manually immediately after the interviews. We iteratively went over the data to locate the overriding themes concerning the components of medical culture, the notion of professional culture and organisational culture, and the dominant culture in the medical practices. We used CDA to identify and analyse eight professional dynamics (duties and responsibilities) among Nigerian healthcare practitioners. These dynamics include professional values and beliefs, professional rules and regulations, professional ethics, eagerness to fulfil the Hippocratic Oath, professional language, professional symbols, medicine codes of practice, 
and societal expectations. The medical culture is strongly built on these professional dynamics. In terms of operationalising CDA, we use the texts extracted from the data sources - focus groups and interview - as a reflection of professional culture, which influences the organisational culture in Nigeria (Fairclough, 1992, 2014). CDA provides the linguistic tool that helps us to understand the legitimatisation of professional culture over organisational culture through discourse (Wodak, 2000).

As a framework for understanding text and context (Wodak and Meyer, 2009), CDA interrogates how rhetoric enables an understanding of how power discourses are constructed, reproduced and legitimised institutionally (Fairclough, 2003). This is what Lawton (2013, p. 107) refers to as understanding 'language in use'.

After conscientiously reviewing the text corpuses, three discursive strategies were consistent in the data and therefore deserve exploration. They also portray intertextuality (congruence) in themes from different sources (Kristeva, 1980). This process is what Dijk (2008) calls thematic 'coherence', which Wolf (2004) equates with the 'single kernel' recognisable pattern that shapes lexical patterning. Lexical patterning deals with word choice and word creation strategies (Fairclough, 2014). Lexical patterning i.e. lexicalisation helps to explain the meso and macro-level issues that are implicit in the use of language (a micro level issue). Lexicalisation refers to systems in ideology, which is a mosaic of cultural conventions, economic, social, and political belief systems as well as institutional norms and values (Van Dijk, 2008a, 2008b).

In fact, Lassen et al. (2006) advised that we must peep into the fundamental ideological connotation behind every piece of communication (discourse) so as to appropriately understand rationale for choice of word (lexical choices). Lexis is level of linguistic coding in text creation, at which truths can be embodied (or misrepresented) with a good measure of freedom and leverage. Therefore, central to lexicalisation (semantic-functional analysis) is that social cognition is formed and shaped by internal mental structures, such as language, which are created as people draw inferences and gather information about their social environment (Carley, 1992). CDA helps to understand thematic relationships that exist in language choice and links them to wider societal issues (Wodak and Meyer, 2009; Fairclough 1992; 2003).

\section{Data Source}

We used a multi-method qualitative study (MMQS). This method encourages the use of multiple data sources (Saunders et al., 2012), which is essentially a mixture of semi-structured 
interviews and focus groups. With the aim of ensuring anonymity and confidentiality, participants' information was coded (Bryman, 2012).

\section{Insert Table 2 about here}

\section{Research Findings}

The findings of this study reveal the significance of professional culture over organisational culture in health organisations. Medical doctors place a huge importance on their professional culture, which is predicated on the dynamics of various duties and responsibilities. Three main themes emerged from the data: (1) the components of medical culture, (b) the notion of professional culture and organisational culture, and (c) the dominant culture. These themes are deeply embedded in the medical doctors' professional culture and are stronger than the health organisation's (hospital) culture. As this is a semantic-functional study, driven by function and meaning of words, our analysis focuses on meaning of lexes (Leech and Short, 2007).

\section{Components of Medical Culture}

Broad and detailed interviews with Nigerian health professionals (doctors) revealed that medical professional culture is replete with sundry fundamental strands of duties and responsibilities, all of which conflate to form the culture to which every medical professional must strictly adhere. These duties include professional beliefs, professional rules and regulations, professional ethics, compliance with the Hippocratic Oath, societal expectations, and the profession's esoteric language, symbols and codes of practice. It is implicit that the medical profession has some age-old norms and practices that are laid down by generations of doctors and that have come to be the embedded culture of the profession. The Hippocratic Oath is an historic oath taken by medical doctors. The oath binds and compels medical doctors to uphold certain ethical standards. The Hippocratic Oath is historical, espousing the traditional values of the medical profession, and it is considered a rite of passage for practitioners of medicine around the world. However, the modern version of the Hippocratic Oath varies from one country to another. The Oath was written about 2,500 years ago and is required from medical students upon graduation or receiving a licence to practice medicine. Everything in it is about medical doctors' conduct, principles, rules, and practices, and they are obliged to follow everything therein to the letter. For instance, a part of the Hippocratic Oath stipulates that 'I will use treatment for the benefit of the ill in accordance with my ability and my judgment, but from what is to harm and injustice I will keep them...About whatever I may see 
or hear in treatment, or even without treatment, in the life of human beings, I will remain silent, holding such thing to be unutterable' (see Sokol, 2008; Miles, 2004). One participant said:

The Hippocratic Oath is a ritual that must be performed and followed by every medical doctor...It is an important culture of the medical profession...perhaps the most important (AM1).

The importance of the Hippocratic Oath as one of the components of medical professional culture cannot be overstated, and health professionals (medical doctors) hold it in very high esteem. Furthermore, medical doctors have symbols that differentiate them from laypersons and members of other professions. The symbols are universal so that members of the medical profession are readily recognisable. According to a participant:

Medicine is characterised by certain symbols that, over the years, have become part of the medical culture. The caduceus badge, the long white coat with a stethoscope loosely carried around doctors' neck. These symbols are exclusively medical, and they are part of medical professional culture everywhere in the world (AM3).

This assertion that the symbols of medicine are universal and are part of the medical profession's culture is echoed by Greenwood (1957) and further supported by Helmreich and Merritt (1998). Codes of practice are another component of medical professional culture. It is a framework for good practice in management in medicine, developed to promote safety and define healthcare workers' responsibilities. It varies among hospitals depending on the specialities of the hospital. One respondent said:

The medical codes of practice are aimed at ensuring that health professionals operate in a professional, ethical, and transparent manner and that they also provide society with robust and high-quality healthcare services...medical codes of conduct are as old as the profession itself, and they are part and parcel of the profession's culture. In fact, strict adherence to them is what defines a physician as an excellent medical doctor (GMF6).

Professional values and beliefs are also part of medical professional culture, and according to one participant, professional values and beliefs are abstract and learnt subconsciously in medicine. The participant explains:

Professional values and beliefs are abstract. They are not necessarily thought about in medical schools but medical doctors learn them through observational learning...they are passed down from generation to generation of doctors. Somehow, they are part of medical professional culture (DM8). 
The medical profession has rules and regulations that guide it and vary from one country to another. Even within the same country, the rules and regulations sometimes vary from one state or county to another. These rules and regulations bind health professionals' conduct and practices that must be firmly adhered to. A participant summed it up as follows:

Medicine has an age-old culture...this culture is an amalgamation of different medical norms, such as the Hippocratic Oath, professional ethics, professional rules and regulations, professional values and beliefs, the symbols, language, and the codes of practice, and of course societal expectations... all of these form a very strong medical professional culture (ZMF7).

This statement resonates with the Office of Minority Health (2002) and Boutin-Forster's (2008) meaning of culture as an integrated pattern of human behaviour, which includes language, thoughts, communications, actions, beliefs, customs, values, and the institution of racial, ethnic, religious, or social groups. Overall, all the components are the constituents of medical professional culture, and medical professionals (medical doctors) clearly state that they form a very strong medical culture. Essentially, the discursive instrumentality of CDA facilitates harmonising these components in order to help deepen our understanding (Wodak and Meyer, 2009) of the reality of medical culture in Nigeria. According to Fairclough (2000), discourse is a definite way of talking and understanding the world that explains the impact of language (a micro-level element) on depicting organisational action through discourse (a meso-level element) (Fairclough, 2000), including the doctors' practices and standards, which in turn reflect social realities (a macro-level element) (Wodak and Meyer, 2009).

\section{The Notion of Professional Culture and Organisational Culture}

Medical doctors define professional culture as an amalgamation of the profession's beliefs, values, symbols, language, codes of practice, rules and regulations, with the Hippocratic Oath as a major part of the culture. The participants believe that organisational culture in health organisations deals very much with administrative issues rather than operational matters. The following quotations typify the shared views of the interviewees:

Medical professional culture is a combination of medical profession's age-old rules and regulations, the Hippocratic Oath, values and beliefs, medical codes of conduct, and our symbols and unique language... all these form our professional culture that, to me, is also the health organisational culture (BM5; the majority of the respondents shared the same view).

Another participant commented: 
The culture of the medical profession combines all the dos and don'ts in medicine that include the Oath doctors swear to at the end of their studies in medical school...doctors are expected to act and practice within the confinements of these rules and regulations...they are the professional culture of medicine and, if you like, they are also the organisational culture (FM10; This view is shared by many participants).

A surgeon who is also the chief medical director of the hospital commented:

Most doctors will tell you that medical professional culture is also its organisational culture, because doctors are bound to the culture of their profession...However, there is a bit of a difference between the two...medical professional culture is the combination of all medical norms, rules, and regulations, including our values, beliefs, symbols, languages, professional ethics, medical practice codes of conduct, the Hippocratic Oath, and societal expectations. All these come together to form the medical professional culture, and it has been like that for ages, while the organisational culture of a health organisation deals with the managerial and administrative issues (GM13).

The above quotes reflect the views of medical doctors regarding professional culture and organisational culture. An overwhelming majority of the participants share the same opinion as the gynaecologist (GM13). They believe that there is no difference between the culture of the medical profession and its organisational culture because every medical doctor is bound to the medical profession's culture. However, very few respondents who are also involved in the management of their hospitals consider that there are slight differences between professional culture and organisational culture in medicine, and they categorically stated that medicine's professional culture should be given the highest priority in a possible event of conflict. A participant reported that:

I do believe that there is a slight difference between medicine's professional culture and its organisational culture...I hold this opinion probably because I am also part of the hospital management team. Medicine profession's culture encompasses all the medical norms, rules, and regulations regarding medical practice, the symbols, the language, the dress, and the medical codes of practice. Meanwhile, organisational culture includes administrative issues and how the hospital is managed. However, whenever there is a conflict between the two cultures, the medical professional culture gets the highest priority (AMF1).

A participant shared her experience about how the medical professional culture overrides its organisational culture when the two cultures clash: 
There was an emergency while I was on duty a few months ago. A pregnant woman was involved in an accident and an immediate operation was urgently required to save her life and that of her unborn child...the culture of the hospital is that $50 \%$ of the operation's fee must be paid before the operation, but the woman had no money on her and she was bleeding quite profusely. I had to snub the organisational culture and went ahead with the operation, even though the hospital manager, who is not a medical doctor, was very angry with me (DM9).

Participants employed what Fairclough (2014) described as a discursive strategy to attenuate 'the consequences of the uneven enforcement' (Wood, 2008, p. 329) of organisational directives in Nigeria.

Short phrases and lexes such as snub...organisational culture... (DM9), profession's culture encompasses... all medical norms, rules, and regulations (AMF1) hallmark the lexical patterning in CDA (Wodak and Meyer, 2009). They demonstrate forceful confirmation (Laine, 2010) that most medical doctors believe that medical professional culture is the same as its organisational culture. This notion prevails among health professionals because medical professional culture is rampant in health organisations and pervades every activity in medicine.

Furthermore, CDA has played an important role in uncovering the thematic relationship existing in language choice (Fairclough, 2014). For instance, for the minority who believe there is a slight difference between the two cultures (AMF1), professional culture is given priority in an event of a conflict. As it can be noted from the above, CDA helps clarify how sociocultural and professional knowledge can be linked to the performance of what Wodak and Meyer (2009) referred to as 'speech act'. For instance, a participant also recalled an incident in which the two cultures clashed and how professional culture was given the highest priority (DM9). These findings resonate with the claims of Helmreich and Merritt (1998) that medicine as a profession has a strong and distinct culture. They further argue that the members of a professional culture such as medicine often place high value on the norms of their profession.

\section{The Dominant Culture}

An overwhelming majority of the respondents said that the medical profession's culture dominates all health organisations (hospitals). The participants believe that the medical profession is unlike all other professions because it deals with human lives. According to them, there are rules, regulations, and procedures that guide medical professionals and all these rules and regulations must be followed to the letter in order for medical professionals to successfully 
perform and fulfil their functions as lifesavers. The following quotation typifies their shared views:

In this hospital and as in every other hospital in which I have worked in the past 21 years, medical professional culture is dominant over any other culture that may exist in the hospital. This is simply because the medical profession has a traditional ageold and very strong culture... (WMF5).

It is evident from the above statement, the use of 'expert witness' (Vaara et al., 2006) is a discursive stratagem to foreground socially sanctioned, professional conduct, hence, use of preexisting narrative (expert testimonial) as a fountain of logic (Leeuwen, 2007). This strategy helps us validate that medical doctors have an age-old professional culture that defines their professionalism, identifies them as healers and lifesavers, and which is dominant in their organisation. In other words, the dominance of the medical professional culture in health organisations cannot be divorced from true medicine professionalism (see Helmreich and Merritt, 1998). This finding is consistent with Ott's (1989) argument that the culture of any organisation dominated by professionals will be dominated by that professional culture.

Doctors are professionals, and we have the liberty to question any administrative rules, laws, and/or opinions that stand at variance with medical professional culture...Let me put it straight for you: health organisational culture is developed to suit the medicine profession's culture... and because health organisations are dominated by medical professionals, medical professional culture is always dominant (GM12).

The above extracts inhere lexes of dominance in which professional culture is discursively assumed to have dominance over organisational culture. Essentially, this demonstrates how the mechanics of CDA and the instrumentality of lexical patterning (Wodak and Meyer, 2009) can help provide a critical perspective in organisational discourse and practice (Fairclough, 2014). Lexical items, such as 'professionals' and 'liberty to question' help us paint a picture of the ethical practices (Fairclough, 2014) that underpin professional culture, which influences organisational culture (Pfister, 2009). This finding is shared by Freidson (1970) and Raelin (1986). Professionals such as medical doctors have special rights in organisations due to their status as professionals. These rights, as argued by Raelin (1986, p. 147), include discretion over many of the parameters of one's work and the freedom to question management regarding decisions affecting professional endeavours. The data analysis concerning this perspective, overall, suggests that medical professional culture is dominant over every other culture that 
may exist alongside it in an organisation. What follows is a discussion and conclusion of the study.

\section{Discussion and Conclusion}

Following a careful evaluation of the studies on professional and organisational culture, it has emerged that while there is much evidence of the relationship between organisational culture and employee performance and between leadership style and performance and so on (see Denison, 1990; Jabeen and Isakovic, 2018; Kotter and Heskett, 1992; Ogbonna and Harris, 2000), studies on the interplay between professional culture and organisational culture has been lacking. Furthermore, we argue that the discursive aspect of understanding this interplay, which CDA's lexical instrumentality helps to facilitate (Fairclough, 2014), is crucial in this study.

As demonstrated in this work, CDA offers a critical perspective on organisational reality (Wodak and Meyer, 2009) and essentially highlights the relations of causality and the discursive practices, events, and texts as well as the wider cultural structures to investigate how such practices arise and are ideologically shaped (Fairclough, 2014). This approach has been empirically explored in organisational behaviour studies (Francis, 2007). Using CDA, we have provided an insight into the power of linguistic resources employed by organisations to portray a positive self-image by legitimising culture and behaviour (Koca-Helvaci, 2015), in this context, professional culture (Scott et al., 2003).

This approach is a way of responding to the call by Bailey et al. (2009), Legge (1995), and Watson (2004) to expand the confines of the literature on employment relations and organisational behaviour in order to trigger a renewed consciousness in management among other social science studies.

In the main, this study has provided a valuable understanding of the interaction between organisational culture and professional culture in Nigerian healthcare organisations. The aim of the study has been to identify the major components of medicine professional culture and examine the interplay between professional culture and organisational culture. The findings suggest that there is a very strong professional culture in medicine, and medical professionals (doctors) ascribe great importance to their profession's culture.

The findings also revealed sundry components of medical professional culture, all of which combine to form the medical professional culture. It is interesting to note that most of the components of medical professional culture are traditional, historic, and age-old practices. For 
instance, the participants spoke of the importance of Hippocratic Oath as a vital component of the medical professional culture. The Hippocratic Oath has been around for more than 2,500 years. It is considered the bedrock of the medical profession's rules and regulations. The study also revealed other important components of medical professional culture to demonstrate what makes medical professional culture strong and formidable.

A key contribution of this study is derived from the insight that despite that professional culture is a subculture of organisational culture, the professional culture of medicine is strong and dominates organisational culture. For example, medical doctors have the liberty to shun the bureaucracy and administrative rules of organisational culture and uphold the value of their professional culture in cases in which the two cultures clash. This resonates with Danielsson et al.'s (2018) findings that professional subcultures in healthcare are very important for patient safety.

This finding confirms the work of Raelin (1985, p. 163), who stated 'there is perhaps no greater source of strain between managers and professionals than over the conflict between bureaucratic and professional standards'. He thus argues that professionals, in the event of a conflict, are permitted to uphold the purity of their professional knowledge without the contamination of bureaucratic conditions in order to raise the standards of excellence in their profession. This study also revealed that medical doctors respect their professional culture so much that the overwhelming majority of them believe that medicine's professional culture is the same as its organisational culture. Only a few who are also involved in the managerial activities of the hospitals know that there are differences between the two cultures.

An intriguing finding of this study revealed that the interplay between professional culture and organisational culture resides in the fact that professional culture is a subculture of organisational culture and that the two cultures are interwoven. Nevertheless, this study argues that a strong professional culture, such as that of the medical profession, dominates the bureaucracy and administrative rules and procedures of organisational culture. Helmreich and Merrit (1998) note that medicine has a very strong culture that its members are proud of and strictly adhere to. While this study is bound by the context of the research environment, future research could replicate the study in different professions and contexts. It is hoped that this study will stimulate further research and debate that will further broaden our understanding of professional and organisational culture, especially in the global south.

\section{Practical Implications}


There is increasing interest in managing organisational culture as a lever for healthcare improvement (Scott et al., 2003). We have also contended that CDA provides a finer-grained and useful framework for understanding the cultural interplay and organisational practice in healthcare organisations (Wodak and Meyer, 2009). In applying CDA (Wodak, 2001; Fairclough, 2003) to the empirical data from Nigerian medical practitioners, this study however, revealed that professional culture often overrides organisational culture in healthcare organisations. Changing medical professional culture to conform to health organisational culture is difficult and risky due to the professional values, affirmed over centuries, which have been embedded into the fabric of medicine's professional culture (Scott et al., 2003).

The primacy of professional culture over organisational culture may have dysfunctional consequences for HRM as medical practitioners are obliged to stick to medical professional culture over human resources practices. Hence, human resources departments may struggle to cope with the behavioural issues that arise due to the dominant position taken by the medical practitioners. This is because the cultural system (professional culture), which is the configuration of beliefs, perceived values, code of ethics, practices, etc. shared by medical doctors, subverts the operating system, which is a significant implication for this study. According to Bloor and Dawson (1994), professional cultures are difficult to replace. Therefore, in the case of healthcare organisations, HRM should support and enhance the cultural system (medicine professional culture) by offering compatible operating strategies and practices. This would create an enabling environment in which both professional and organisational goals will be achieved.

\section{References}

ACAS. (2012), Voice and Participation in the Modern Workplace: challenges and prospects. ACAS Future of Workplace Relations. Discussion Paper Series. Http://www.acas.org.uk/.../Voice and Participation in the Modern Workplace challenges. (Accessed 16/01/2017).

Alvesson, M. and Deetz, S. (2000), Doing critical management research. London: Sage.

Bailey, J., Townsend, K. and Luck, E. (2009), Work choices, image choices and the marketing of new industrial relations legislation. Work, Employment and Society, Vol. 23, No. 2, pp. $285-$ 304.

Bedzow, I. (2019), The challenge of creating a professional culture. Society for Human Resource Management (SHRM), Available at https://blog.hrps.org/blogpost/The-Challengeof-Creating-a-Professional-Culture. Accessed January 2020. 
Bloor. G. and Dawson, P. (1994), Understanding professional culture in organisational context. Organisational Studies, Vol. 15, No. 2, pp. 275-295.

Bourn, M and Ezzamel, M. (1986), Organisational culture in hospitals in the National Health Service. Financial Accountability and Management, Vol. 2, No. 3, pp. 203-225.

Boutin-Foster, C., Foster, J. C. and Konopasek, L. (2008), Physician, know thyself: the professional culture of medicine as a framework for teaching cultural competence. Academic Medicine, Vol. 83, No. 1, pp. 106-111.

Boyatzis, R. (1982), The Competent Manager: A Model for Effective Performance. New York, NY: John Wiley and Sons.

Bray, M., Deery, S., Walsh, J. and Waring, P. (2005), Industrial relations: A contemporary approach. ( $3^{\text {rd }}$ edn). Sydney: McGraw-Hill.

Bryman, A. (2012), Social research methods. (4th edn). New York: Oxford University Press.

Brien, A. (1998), Professional ethics and the culture of trust. Journal of Business Ethics, Vol. 17, No. 4, pp. 391-409.

Carley, K. and Palmquist, M. (1992), Extracting, representing, and analysing mental models. Social forces, Vol. 70, No. 3, pp. 601-636.

Danielsson, M., Nilsen, P., Rutberg, H. and Carlford, S. (2018), The professional culture among physicians in Sweden: potential implications for patient safety. BMC Health Services Research, Vol. 18, No. 543, pp. 1-9.

Day, G. E. (2020), Understanding organisational culture in the hospital setting. In E. Chang, J. Daly (Eds), Transitions in nursing: Preparing for professional practice (59-76). Chatswood, Australia; Elsevier.

Degeling, P., Kennedy, J. and Hill, M. (2001), Mediating the cultural boundaries between medicine, nursing and management-the central challenge in the hospital reform. Health Service Management Research, Vol. 14, No. 1, pp. 36-48.

Denison, D. R. (1990), Corporate culture and organisational effectiveness. New York: Wiley.

Deshpande, R. and Webster, F. Jr (1989), 'Organizational culture and marketing: defining the research agenda'. Journal of Marketing, Vol. 53, No. 1, pp. 3-15.

Fairclough, N. (2014), Critical language awareness. London: Routledge.

Fairclough, N. (2003), Analysing discourse: textual analysis for social research. London: Routledge.

Fairclough, N. (1992), Discourse and social change. Oxford: Blackwell.

Fairclough, N. (1995). Critical discourse analysis: The critical study of language. London: Longman. 
Fairclough, N. and Wodak, R. (1997), Critical discourse analysis. In T. van Dijk (Ed.), Discourse as social interaction: Discourse studies (pp. 258-284). London: Sage.

Ford, M. and Gillan, M. (2016), Employment relations and the state in Southeast Asia. Journal of Industrial Relations, Vol. 58, No. 2, pp.167-182.

Francis, H. (2007), Discursive struggle and the ambiguous world of HRD. Advances in Developing Human Resources, Vol. 9, No. 1, pp.83-96.

Freidson, E. (1970), Profession of medicine: A study of the sociology of dominance: The social structure of medical care. New York: Aldine.

Glaser, B. G. and Strauss, A. L. (1967), The discovery of grounded theory, New York: Aldine de Gruyter.

Goode, W. J. (1957), Community within community: The professions. American Sociological Review, Vol. 22, No. 2, pp. 194-200.

Graham, P. and Luke, A. (2011), Critical discourse analysis and political economy of communication: Understanding the new corporate order. Cultural Politics, Vol. 7, No. 1, pp.103-132.

Greenwood, E. (1957), ‘Attributes of a profession'. Social Work, Vol. 2, No. 3, 45-55.

Hall, P. (2005), 'Interprofessional teamwork: professional cultures as barriers. Journal of Interprofessional Care, Vol. 19, No. 1, pp. 188-196.

Helmreich, R. L. and Merritt, A. C. (1998), Culture at work in aviation and medicine: National, Organisational and professional influences. England. Ashgate Publishing Limited.

Herkenhoff, L. M. (2010), Professional culture, emotional intelligence and emotional process model. Journal of Organisational Leadership and Business, pp. 1-30.

Hofstede, G. (1980), Culture's consequences: International differences in work related values, Sage Publications, Thousand Oaks, CA.

Hofstede, G (1991), Cultures and organizations, London, Harper Collins.

Hughes, D. (1958), Men and their work. New York: Free Press.

Ireland, R. D. and Hitt, M. A. (1999), 'Achieving and maintaining strategic competitiveness in the $21^{\text {st }}$ century: The role of strategic leadership. Academy of Management Executive, Vol. 13, No. 1, pp. 43-57.

Jabeen, F and Isakovic, A. A. (2018), "Examining the impact of organizational culture on trust and career satisfaction in the UAE public sector: A competing values perspective", Employee Relations, Vol. 40, No. 6, pp. 1036-1053. 
Janus, K. and Browning, S. L. (2014), The effects of professional culture on intrinsic motivation among physicians in an academic medical centre. Journal of Healthcare Management, Vol. 59, No. 4, pp. 287-304.

Karassavidou, E., and Glaveli, N. (2011), Assessing hospital's readiness for clinical governance quality initiatives through organisational climate. Journal of Health Organisation and Management, Vol. 25, No. 2, pp. 214-240.

Kessler, I. and Purcell, J. (1996), The value of joint working parties. Work, Employment and Society, 10, 4, 663-682.

Koca-Helvaci, Z.C. (2015), Walmart and its employee relations: organisational stance-taking and legitimacy. On the Horizon, Vol. 23, No. 4, pp. $374-386$.

Kotter, J. and Heskett, J. (1992), Corporate culture and performance. New York: Macmillan.

Kristeva, J. (1980), Desire in language: A semiotic approach to literature and art. New York: Columbia University Press.

Krueger, R. A. and Casey, M.A. (2000), Focus groups: A practical guide for applied research. Los Angeles.

Laine, M. (2010), Towards sustaining the status quo: Business talk of sustainability in Finnish corporate disclosures 1987-2005. European Accounting Review, No. 19, No. 2, pp. 247-274.

Lawton, R. (2013), Speak English or go home: The anti-immigrant discourse of the American 'English only' movement. CADAAD, Vol. 7, No. 1, pp.100-122.

Lassen, I., Strunck, J. and Vestergaard, T. (2006), (Eds). Mediating ideology in text and image: ten critical studies (pp. 19-35). Amsterdam: John Benjamins.

Leech, G. and Short, M. (2007), Style in fiction: A linguistic introduction to English fictional Prose. ( ${ }^{\text {nd }}$ Ed.). London: Longman.

Leeuwen, T. V. (2007), Legitimation in discourse and communication. Discourse and Communication, Vol. 1, No. 1, pp. 91-112.

Legge, K. (1995), Human resource management: Rhetoric and realities. London: Macmillan.

Mathew, (2019), "Organisational culture and effectiveness", Employee Relations, Vol. 41, No. 3, pp. 538-551.

McDermott, R. and O'Dell, C. (2001), 'Overcoming cultural barriers to sharing knowledge'. Journal of Knowledge Management, Vol. 5, No. 1, pp. 76-85.

Miles, S. H. (2004), The Hippocratic Oath and the ethics of medicine. Oxford University Press; Oxford, New York.

Montgomery, A., Panagopoulou, E., Kehoe, I. and Valkanos, E. (2011), Connecting organisational culture and quality of care in the hospital: is job burnout the missing link? Journal of Health Organisation and Management, Vol. 25, No. 1, pp. 108-123. 
Morgan, P. I. and Ogbonna, E. (2008), Subcultural dynamics in transformation: A multiperspective study of healthcare professionals. Human Relations, Vol. 61, No. 1, pp. 39-65.

Office of Minority Health, U. S. Department of Health and Humanity Services (2002), Teaching cultural competence in health care: A review of current concepts, policies, and practices. Washington DC.

Ogbonna, E. and Harris, L. C. (2014), Organisational cultural perpetuation: A case study of an English premier league football club. British Journal of Management, Vol. 25, No. 4, pp. 667686.

Ogbonna, E. and Harris, L. C. (2000), Leadership style, organisational culture and performance: empirical evidence from UK companies. International Journal of Human resource Management, Vol. 11, No. 4, pp. 766-788.

Okpu, T. (2016), Employee voice and workers commitment in Nigerian workplace. Lap Lambert Academic Publishing.

Ott, J. S. (1989), The organisational culture perspective. Chicago, IL: Dorsey Press.

Parker, M. (2000), Organisational culture and identity. London: Sage.

Patton, M. Q. (2012), Qualitative research and evaluation methods. London: Sage.

Peled-Elhanan, N. (2010), Legitimation of massacres in Israeli school history books. Discourse and Society, Vol. 21, No. 4, pp. 377-404.

Pfister, J. A. (2009), Managing organisational culture for effective control: From practice to theory. Berlin: Physica.

Pinho, J. C., Rodrigues, A. P. and Dibb, S. (2014), The role of corporate culture, market orientation and organisational commitment in organisational performance: The case of nonprofit organisations. Journal of Management Development, Vol. 33, No. 4, pp. 374-398.

Raelin, J. A. (1985), The basis for the professional's resistance to managerial control. Human Resource Management, Vol. 24, No. 2, pp. 147-176.

Rapisarda, F., Corbiere, M., Lesage, A. D., De Benedicts, L., Pelletier, J. F., Felx, A., Leblanc, Y., Vallarino, M. and Miglioretti, M. (2020), Development and validation of the mental health professional culture inventory. Epidemiology and Psychiatric Sciences, Vol. 29, No. 80, pp. 19 .

Rathert, C., Ishqaidef, G. and May, D. (2009), 'Improving work environment in health care: test of a theoretical framework'. Health Care Management Review, Vol. 34, No. 4, pp. 334343.

Riivari, E., Lamsa, A., Kujala, J. and Heiskanen, E. (2012), The ethical culture of organisations and organisational innovativeness. European Journal of Innovation Management, Vol. 15, No. 3, pp. 310-331. 
Saunders, M., Lewis, P. and Thornhill, A. (2012), Research methods for business students. ( $8^{\text {th }}$ ed). Harlow: Pearson.

Schein, E. (2010), Organisational Culture and Leadership, San Francisco, CA: Jossey-Bass.

Schein, E. (1985), Organisational Culture and Leadership, San Francisco, CA: Jossey-Bass.

Schein, E. (1984), Coming to a new awareness of organisational culture. Sloan Management Review, Vol. 25, No. 2, pp. 3-16.

Scott, T., Mannion, R., Davies, H. and Marshall, M. (2003), Implementing culture change in health care: theory and practice. International Journal for Quality in Health Care, Vol. 15, No. 2, pp. 111-118.

Silverman, D. (2006), Interpreting qualitative data. ( $3^{\text {rd }}$ ed.). London: Sage.

Smith, M. A. and Webster, D. M. (2009), 'Using culture and climate to optimise care'. Family Medicine, Vol. 41, No. 3, pp. 208-209.

Smircich, L. (1983), Studying organisations as cultures. In G. Morgan (Ed.), Beyond method strategies for social research (pp. 160-172) London: Sage.

Sokol, D. (2008), A guide to the Hippocratic Oath. Available at http://news.bbc.co.uk/1/hi/7654432.stm. Assessed on 06/01/2015.

Speroff, T., Nwosu, S., Greevy, R., Weinger, M. B., Talbot, T. R., Wall, R. J., Deshpande, J. K., France, D. J., Ely, E. W., Burgess, H., Englebright, J., Williams, M. V. and Dittus, R. S. (2011), Organisational culture variation across hospitals and connection to patient safety climate. The International Journal of Health Care Improvement, Vol. 19, No. 6, pp. 592-596.

Sun, S. (2008), Organisational culture and its themes. International Journal of Business and Management, Vol. 3, No. 12, pp. 137-141.

Torsello, D. (2019), “Generation Y workers”, Employee Relations, Vol. 41 No. 6, pp. 1330-1347.

Van Dijk, T. A. (2008a), Discourse and Context: A Socio-cognitive Approach. Cambridge and New York: Cambridge University Press.

Van Dijk, T. A. (2008b), Discourse and Power. Basingstoke and New York: Palgrave Macmillan

Van Maanen, J. and Barley, S. R. (1984), Occupational communities: Culture and control in organisations. In B. Staw and L. L. Cummings (Eds.), Research in organisational behaviour (pp. 287-365). Greenwich, CT: JAI Press.

Van Maanen, J. and Barley, S. R. (1985), Cultural organisation: Fragments of a theory. In P. Frost, L. Moore, M. Louis, C. Lundberg, and J. Martin (Eds.), Organisational culture (pp. 3153) Beverly Hills, CA: Sage.

Vaara, E. and Tienari, J. (2008), A discursive perspective on legitimation strategies in MNCs. Academy of Management Review, Vol. 33, No. 4, pp. 985-993. 
Vaara, E., Tienari, J., and Laurila, J. (2006), Pulp and paper fiction: On the discursive legitimation of global industrial restructuring. Organisation Studies, Vol. 27, No. 6, pp. 789810.

Watson, T. J. (2004), HRM and critical social science analysis. Journal of Management Studies, Vol. 41, No. 3, pp.447-467.

Wodak, R. and Meyer, M. (2009), Methods for critical discourse analysis. (2 ${ }^{\text {nd }}$ Ed.). London: Sage.

Wodak, R. (2001), The discourse-historical approach. In: R. Wodak and M. Meyer (Eds.). Methods of Critical Discourse Analysis (pp. 63-95) London: Sage.

Wodak, R. (2000), La sociolingüística necesita una teoría social? Nuevas perspectivas en el análisis crítico del discurso. Discursoy Sociedad, Vol. 2, No. 3, pp. 123-147.

Wolf, W. (2004). Cross the border-close that gap: Towards an intermedia narratology. European Journal of English Studies, Vol. 8, No. 1, pp. 81-103.

Worldometers (2020). Nigerian population. Available at https://www.worldometers.info/world-population/nigeria-population/. Accessed January 2020.

Worrall. L., Parkes, C. and Cooper, C. L. (2004), 'The impact of organizational change on the perceptions of UK manager'. European Journal of Work and Organisational Psychology, Vol. 13, No. 2, pp. 139-163. 
Table 1: Semi-Structured Interviews Brief

\begin{tabular}{|l|c|c|c|c|c|c|}
\hline $\begin{array}{c}\text { Serial } \\
\text { no }\end{array}$ & Codes & $\begin{array}{c}\text { Name of } \\
\text { Hospital }\end{array}$ & Age & Gender & $\begin{array}{c}\text { Years of } \\
\text { Experience }\end{array}$ & Specialties \\
\hline \multicolumn{7}{|c|}{ Public Hospitals } \\
\hline 1 & AM1 & Amo-Hosp. & 43 & F & 12 & Gynaecology \\
\hline 2 & AM2 & Amo-Hosp. & 46 & M & 16 & Cardiology \\
\hline 3 & AM3 & Amo-Hosp. & 29 & F & 6 & Obstetrics \\
\hline 4 & BM4 & Bamo-Hosp. & 37 & M & 12 & Haematology \\
\hline 5 & BM5 & Bamo-Hosp. & 42 & M & 14 & Paediatrics \\
\hline 6 & CM6 & Camo-Hosp. & 54 & F & 13 & Family Medicine \\
\hline 7 & CM7 & Camo-Hosp. & 45 & M & 15 & Radiologist \\
\hline 8 & DM8 & Damo-Hosp. & 52 & M & 12 & Surgeon \\
\hline 9 & DM9 & Damo-Hosp. & 49 & F & 4 & Cardiology \\
\hline 10 & FM10 & Famo-Hosp. & 55 & M & 6 & Family Medicine \\
\hline 11 & FM11 & Famo-Hosp. & 59 & M & 16 & Family Medicine \\
\hline 12 & GM12 & Gamo-Hosp. & 44 & F & 18 & Surgeon \\
\hline 13 & GM13 & Gamo-Hosp. & 29 & M & 13 & Cardiology \\
\hline 25 & PM24 & Pano-Hosp. & 41 & M & 11 & Surgeon \\
\hline $\begin{array}{l}\text { Key guide: } \\
\text { Public Hospitals: AM, BM, CM, DM, FM and GM, } \\
\text { Private Hospitals: HM, JM, KM, LM, NM, MM \& PM }\end{array}$ \\
\hline \begin{tabular}{l}
$\mid l$ \\
\hline
\end{tabular}
\end{tabular}

